Article

\title{
On Hybrid Contractions in the Context of Quasi-Metric Spaces
}

\author{
Andreea Fulga $1, *,+\left(\mathbb{D}\right.$, Erdal Karapınar $2,3, *,+\left[\right.$ ib and Gabriela Petruşel ${ }^{4,+}$ \\ 1 Department of Mathematics and Computer Science, Transilvania University of Brasov, 500036 Brasov, Romania \\ 2 Department of Medical Research, China Medical University Hospital, China Medical University, \\ Taichung 40402, Taiwan \\ 3 Department of Mathematics, Çankaya University, Ankara 06790, Turkey \\ 4 Faculty of Business, Babeş-Bolyai University, 400084 Cluj-Napoca, Romania; gabi.petrusel@tbs.ubbcluj.ro \\ * Correspondence: afulga@unitbv.ro (A.F.); karapinar@mail.cmuh.org.tw or erdalkarapinar@yahoo.com (E.K.) \\ + These authors contributed equally to this work.
}

Received: 1 April 2020; Accepted: 27 April 2020; Published: 29 April 2020

\begin{abstract}
In this manuscript, we will investigate the existence of fixed points for mappings that satisfy some hybrid type contraction conditions in the setting of quasi-metric spaces. We provide examples to assure the validity of the given results. The results of this paper generalize several known theorems in the recent literature.
\end{abstract}

Keywords: contractions; hybrid contractions; quasi-metric spaces; metric spaces

\section{Introduction and Preliminaries}

Roughly speaking, a quasi-metric is a distance function that is not symmetry but satisfies both the triangle inequality and self-distance property. The notion of quasi-metric was first introduced by Wilson in 1930s [1]. This is a subject of intensive research not only in the setting of topology [2-4] and functional analysis, but also several qualitative sciences, such as theoretical computer science [5-8], biology [9], and many other qualitative disciplines. In particular, as it is mentioned in [10], the notion of quasi-metric plays crucial roles in several distinct branches of mathematics, such as in the existence and uniqueness of iterated function systems' attractor (fractal), in the existence and uniqueness of Hamilton-Jacobi equations, and so on.

Another crucial notion that has no metric counterpart is that of an engaged partial order. Each partial order can be associated with a quasi-metric, and vice versa. Consequently, quasi-metric not only generalizes the concept of the metric, but also partial orders. This is a crucial fact for both the theoretical computer science applications and also has significance in the framework of biology [9].

For the sake of the completeness, we shall give the formal definition of quasi-metric. Throughout the paper, $x$ is a nonempty set A distance function $q: X \times X \rightarrow[0, \infty)$ is called a quasi-metric on $X$ if

$\left(q_{1}\right) \quad q(u, v)=0 \Leftrightarrow u=v ;$

$\left(q_{2}\right) \quad q(u, w) \leq q(u, v)+q(v, w)$, for all $u, v, w \in X$.

In addition, the pair $(x, q)$ is called a quasi-metric space. 
In what follows, we indicate the close relation between a standard metric and a quasi-metric. Given $q$ be a quasi-metric on $X$, it is clear that the function $q_{*}: x \times x \rightarrow[0, \infty)$ defined by $q_{*}(u, v)=q(v, u)$ forms also a quasi-metric and it is also called the dual (conjugate) of $q$. The functions $d_{1}, d_{2}: x \times x \rightarrow[0, \infty)$, where

$$
\begin{aligned}
& d_{1}(v, u)=q(u, v)+q_{*}(u, v), \\
& d_{2}(v, u)=\max \left\{q(u, v), q_{*}(u, v)\right\}
\end{aligned}
$$

form standard metrics on $x$.

We will provide an overview of quasi-metric spaces, presenting the notions of convergence, completeness, and continuity.

Let $\left\{u_{n}\right\}$ be a sequence in $X$, and $u \in X$, where $(X, q)$ a quasi-metric space. We say that:

1. $\left\{u_{n}\right\}$ converges to $u$ if and only if

$$
\lim _{n \rightarrow \infty} q\left(u_{n}, u\right)=\lim _{n \rightarrow \infty} q\left(u, u_{n}\right)=0 .
$$

2. $\left\{u_{n}\right\}$ is left-Cauchy if and only if for every $\epsilon>0$ there exists a positive integer $k=k(\epsilon)$ such that $q\left(u_{n}, u_{m}\right)<\epsilon$ for all $n \geq m>k$.

3. $\left\{u_{n}\right\}$ is right-Cauchy if and only if for every $\epsilon>0$ there exists a positive integer $k=k(\epsilon)$ such that $q\left(u_{n}, u_{m}\right)<\epsilon$ for all $m \geq n>k$.

4. $\left\{u_{n}\right\}$ is Cauchy if and only if it is left-Cauchy and right-Cauchy.

We would remark here that, in a quasi-metric space $(x, q)$, the limit for a convergent sequence is unique. Indeed, if $u_{n} \rightarrow u$, for all $v \in X$, we have

$$
\lim _{n \rightarrow \infty} q\left(u_{n}, v\right)=q(u, v) \text { and } \lim _{n \rightarrow \infty} q\left(v, u_{n}\right)=q(v, u) .
$$

A quasi-metric space $(x, q)$ is said to be: complete (respectively, left-complete or right-complete) if and only if each Cauchy sequence (respectively, left-Cauchy sequence or right-Cauchy sequence) in $X$ is convergent. Notice, in this context, that "right completeness" is equivalent to "Smyth completeness" [11]. See also [12].

A mapping $T: X \rightarrow X$ is continuous provided that, for any sequence $\left\{u_{n}\right\}$ in $X$ such that $u_{n} \rightarrow u \in X$, the sequence $\left\{T u_{n}\right\}$ converges to $T u$, that is,

$$
\lim _{n \rightarrow \infty} q\left(T u_{n}, T u\right)=\lim _{n \rightarrow \infty} q\left(T u, T u_{n}\right)=0
$$

If $T: x \rightarrow x$, then the fixed point set of $T$ is $\mathcal{F}_{T}(x):=\{x \in x: T x=x\}$.

A mapping $\zeta:[0, \infty) \times[0, \infty) \rightarrow \mathbb{R}$ is called an extended simulation function if the following axioms are fulfilled:

$\left(z_{d}\right) \zeta(t, s)<s-t$ for all $t, s>0$;

$\left(z_{0}\right) \zeta(t, 0) \leq 0$ for every $t \geq 0$ and $\zeta(t, 0)=0 \Leftrightarrow t=0$.

Notice that the axiom $\left(z_{d}\right)$ implies that $\zeta(t, t)<0$ for all $t>0$. Let us denote by $\mathcal{Z}$ the family of all extended simulation functions $\zeta:[0, \infty) \times[0, \infty) \rightarrow \mathbb{R}$.

A function $\varphi:[0, \infty) \rightarrow[0, \infty)$ is called a comparison function [13] if:

$\left(c_{1}\right) \quad \varphi$ is increasing;

$\left(c_{2}\right) \lim _{n \rightarrow \infty} \varphi^{n}(t)=0$, for $t \in[0, \infty)$. 
Proposition 1. If $\varphi$ is a comparison function, then:

(i) each $\varphi^{k}$ is also a comparison function, for all $k \in \mathbb{N}$;

(ii) $\varphi$ is continuous at 0 ;

(iii) $\varphi(0)=0$ and $\varphi(t)<t$ for all $t>0$.

A function $\psi:[0, \infty) \rightarrow[0, \infty)$ is called a c-comparison function $[13,14]$ if:

$\left(c c_{1}\right) \quad \psi$ is increasing;

$\left(c c_{2}\right) \quad \sum_{n=0}^{\infty} \psi^{n}(t)<\infty$, for all $t \in(0, \infty)$.

We denote by $\Psi$ the family of $c$-comparison functions. In some papers, instead of a $c$-comparison function, the term of strong comparison function is used. See [13].

Remark 1. Any c-comparison function is a comparison function.

Let $\alpha: X \times X \rightarrow[0, \infty)$ be a function. We say that a mapping $T: X \rightarrow X$ is $\alpha$-orbital admissible [15] if for each $u \in X$ we have

$$
\alpha(u, T u) \geq 1 \Rightarrow \alpha\left(T u, T^{2} u\right) \geq 1
$$

Lemma 1. Let $T: X \rightarrow X$ be an $\alpha$-orbital admissible function. If there exists $u_{0} \in X$ such that $\alpha\left(u_{0}, T u_{0}\right) \geq 1$ and $\alpha\left(T u_{0}, u_{0}\right) \geq 1$, then the sequence $\left(u_{n}\right)_{n \in \mathbb{N}}$, defined by $u_{n}=T u_{n-1}, n \in \mathbb{N}$ satisfies the following relations:

$$
\alpha\left(u_{n}, u_{n+1}\right) \geq 1 \text { and } \alpha\left(u_{n+1}, u_{n}\right) \geq 1, \text { for all } n \in \mathbb{N}_{0} .
$$

We say that the set $x$ is regular with respect to mapping $\alpha: x \times x \rightarrow[0, \infty)$ if the following condition is satisfied: if $\left\{u_{n}\right\}$ is a sequence in $X$ such that $\alpha\left(u_{n+1}, u_{n}\right) \geq 1$ and $\alpha\left(u_{n}, u_{n+1}\right) \geq 1$ for any $n \in \mathbb{N}$ and $u_{n} \rightarrow u \in X$ as $n \rightarrow \infty$, then there exists a subsequence $\left\{u_{n(i)}\right\}$ of $\left\{u_{n}\right\}$ such that

$$
\alpha\left(u_{n(i)}, u\right) \geq 1 \text { and } \alpha\left(u, u_{n(i)}\right) \geq 1 \text {, }
$$

for each $i$.

In this manuscript, we will investigate the existence of fixed points for mappings that satisfy some hybrid type contraction conditions in the setting of quasi-metric spaces. We provide examples to assure the validity of the given results. The results of this paper generalize several known theorems in the recent literature, see [13,14,16-25].

\section{Main Results}

We start with the formal definition of hybrid almost contraction of type $\mathbb{I}$.

Definition 1. Let $(x, q)$ be a quasi-metric space. We say that the mapping $T: X \rightarrow X$ is a hybrid almost contraction of type $\mathbb{I}$, if there exist $\zeta \in \mathcal{Z}, \psi \in \Psi, p \geq 0, L \geq 0$ and $a_{1}, a_{2}, a_{3} \in[0,1]$ with $a_{1}+a_{2}>0$, $a_{1}+a_{2}+a_{3}=1$, such that, for all distinct $u, v \in X$, we have

$$
\begin{aligned}
& \frac{1}{2} \min \{q(u, T u), q(v, T v) q(T v, v)\} \leq q(u, v) \text { implies } \\
& \quad \zeta\left(\alpha(u, v) q(T u, T v), \psi\left(I_{p}(u, v)+L \mathcal{N}(u, v)\right)\right) \geq 0,
\end{aligned}
$$


where

$$
I_{p}(u, v)=\left\{\begin{aligned}
{\left[a_{1}(q(u, v))^{p}+a_{2}(q(u, T u))^{p}+a_{3}(q(v, T v))^{p}\right]^{1 / p}, } & \text { for } p>0 \\
(q(u, v))^{a_{1}} \cdot(q(u, T u))^{a_{2}} \cdot(q(v, T v))^{a_{3}} & \text { for } p=0
\end{aligned}\right.
$$

and

$$
\mathcal{N}(u, v)=\min \{q(u, T v), q(v, T u)\}
$$

Theorem 1. Let $(x, q)$ be a complete quasi-metric space and $\alpha: x \times x \rightarrow[0, \infty)$ be a mapping such that:

(i) $\quad u=$ Tu implies $\alpha(u, v)>0$ for every $v \in X$;

(ii) $v=T v$ implies $\alpha(u, v)>0$ for every $u \in X$.

Suppose that $T: X \rightarrow X$ is an hybrid almost contraction of type $\mathbb{I}$ and

$\left(C_{1}\right) \quad T$ is $\alpha$-orbital admissible;

$\left(C_{2}\right)$ there exists $u_{0} \in X$ such that $\alpha\left(u_{0}, T u_{0}\right) \geq 1$ and $\alpha\left(T u_{0}, u_{0}\right) \geq 1$;

$\left(C_{3}\right) \quad T$ is continuous.

Then, $T$ has a fixed point.

Proof. Let the sequence $\left\{u_{n}\right\}$ in $X$ be defined by

$$
u_{1}=T u_{0}, u_{2}=T u_{1}, \ldots, u_{n}=T u_{n-1}=T^{n-1} u_{0}
$$

where $u_{0} \in X$ is the point such that, from $\left(C_{2}\right), \alpha\left(u_{0}, T u_{0}\right) \geq 1$ and $\alpha\left(T u_{0}, u_{0}\right) \geq 1$. Indubitably, for all $n \in \mathbb{N}$, we have $u_{n+1} \neq u_{n}$. As a matter of fact, if we suppose that there is $N_{0} \in \mathbb{N}$ such that $u_{N_{0}}=u_{N_{0}+1}$, from the manner in which the sequence $\left\{u_{n}\right\}$ was defined, we get

$$
u_{N_{0}}=T u_{N_{0}}=u_{N_{0}+1}
$$

so that the fixed point of $T$ is $u_{N_{0}}$ and the proof is completed. Thus, choosing $u=u_{n-1}$ respectively $v=u_{n}$ and since $\frac{1}{2} \min \left\{q\left(u_{n-1}, T u_{n-1}\right), q\left(u_{n}, T u_{n}\right), q\left(T u_{n}, u_{n}\right)\right\} \leq \frac{1}{2} q\left(u_{n-1}, T u_{n-1}\right)<q\left(u_{n-1}, u_{n}\right)$ holds for any $n \in \mathbb{N}$, by (3), we get

$$
\zeta\left(\alpha\left(u_{n-1}, u_{n}\right) q\left(T u_{n-1}, T u_{n}\right), \psi\left(I_{p}\left(u_{n-1}, u_{n}\right)+L \mathcal{N}\left(u_{n-1}, u_{n}\right)\right)\right) \geq 0 .
$$

In other words, taking into account $\left(z_{d}\right)$,

$$
0 \leq \psi\left(I_{p}\left(u_{n-1}, u_{n}\right)+L \mathcal{N}\left(u_{n-1}, u_{n}\right)\right)-\alpha\left(u_{n-1}, u_{n}\right) q\left(T u_{n-1}, T u_{n}\right) .
$$

However, $T$ is an $\alpha$-orbital admissible and, on the strength of Lemma 1, the above inequality yields

$$
q\left(T u_{n-1}, T u_{n}\right) \leq \alpha\left(u_{n-1}, u_{n}\right) q\left(T u_{n-1}, T u_{n}\right) \leq \psi\left(I_{p}\left(u_{n-1}, u_{n}\right)+L \mathcal{N}\left(u_{n-1}, u_{n}\right)\right) .
$$

Since

$$
\begin{aligned}
\mathcal{N}\left(u_{n-1}, u_{n}\right) & =\min \left\{q\left(u_{n-1}, T u_{n}\right), q\left(u_{n}, T u_{n-1}\right)\right\} \\
& =\min \left\{q\left(u_{n-1}, u_{n}\right), q\left(u_{n}, u_{n}\right)\right\}=0,
\end{aligned}
$$

the inequality (6) becomes

$$
q\left(T u_{n-1}, T u_{n}\right) \leq \psi\left(I_{p}\left(u_{n-1}, u_{n}\right)\right)
$$


In addition, by taking $u=u_{n}$, respectively, $v=u_{n-1}$, we have

$$
\begin{aligned}
\frac{1}{2} \min \left\{q\left(u_{n}, T u_{n}\right), q\left(u_{n-1}, T u_{n-1}\right), q\left(T u_{n-1}, u_{n-1}\right)\right\} & \leq \frac{1}{2} \min \left\{q\left(u_{n}, u_{n+1}\right), q\left(u_{n-1}, u_{n}\right), q\left(u_{n}, u_{n-1}\right)\right\} \\
& <q\left(u_{n}, u_{n-1}\right) .
\end{aligned}
$$

As a consequence, (3) becomes

$$
\zeta\left(\alpha\left(u_{n}, u_{n-1}\right) q\left(T u_{n}, T u_{n-1}\right), \psi\left(I_{p}\left(u_{n}, u_{n-1}\right)+L \mathcal{N}\left(u_{n}, u_{n-1}\right)\right)\right) \geq 0,
$$

or, taking into account $\left(z_{d}\right)$,

$$
0 \leq \psi\left(I_{p}\left(u_{n}, u_{n-1}\right)+L \mathcal{N}\left(u_{n}, u_{n-1}\right)\right)-\alpha\left(u_{n}, u_{n-1}\right) q\left(T u_{n}, T u_{n-1}\right) .
$$

By Lemma 1, the above inequality yields

$$
\begin{aligned}
q\left(u_{n+1}, u_{n}\right) & =q\left(T u_{n}, T u_{n-1}\right) \leq \alpha\left(u_{n}, u_{n-1}\right) q\left(T u_{n}, T u_{n-1}\right) \\
& \leq \psi\left(I_{p}\left(u_{n}, u_{n-1}\right)+\operatorname{LN}\left(u_{n}, u_{n-1}\right)\right) .
\end{aligned}
$$

However,

$$
\begin{aligned}
\mathcal{N}\left(u_{n}, u_{n-1}\right) & =\min \left\{q\left(u_{n}, T u_{n-1}\right), q\left(u_{n-1}, T u_{n}\right)\right\} \\
& =\min \left\{q\left(u_{n}, u_{n}\right), q\left(u_{n-1}, u_{n+1}\right)\right\}=0,
\end{aligned}
$$

and then we get

$$
q\left(T u_{n}, T u_{n-1}\right) \leq \psi\left(I_{p}\left(u_{n}, u_{n-1}\right)\right)
$$

From this point of the proof, we will consider the two cases separately: $p>0$ and $p=0$.

Case 1. For the case $p>0$,

$$
\begin{aligned}
I_{p}\left(u_{n-1}, u_{n}\right) & =\left[a_{1}\left(q\left(u_{n-1}, u_{n}\right)\right)^{p}+a_{2}\left(q\left(u_{n-1}, T u_{n-1}\right)\right)^{p}+a_{3}\left(q\left(u_{n}, T u_{n}\right)\right)^{p}\right]^{1 / p} \\
& =\left[a_{1}\left(q\left(u_{n-1}, u_{n}\right)\right)^{p}+a_{2}\left(q\left(u_{n-1}, u_{n}\right)\right)^{p}+a_{3}\left(q\left(u_{n}, u_{n+1}\right)\right)^{p}\right]^{1 / p} \\
& =\left[\left(a_{1}+a_{2}\right)\left(q\left(u_{n-1}, u_{n}\right)\right)^{p}+a_{3}\left(q\left(u_{n}, u_{n+1}\right)\right)^{p}\right]^{1 / p}
\end{aligned}
$$

and the inequality (6) becomes

$$
q\left(u_{n}, u_{n+1}\right)=q\left(T u_{n-1}, T u_{n}\right) \leq \psi\left(\left[\left(a_{1}+a_{2}\right)\left(q\left(u_{n-1}, u_{n}\right)\right)^{p}+a_{3}\left(q\left(u_{n}, u_{n+1}\right)\right)^{p}\right]^{1 / p}\right) .
$$

Onward, being a $c$-comparison function, $\psi$ satisfies (iii) by Proposition 1 that is $\psi(t)<t$ for any $t>0$, we obtain

$$
\begin{aligned}
q\left(u_{n}, u_{n+1}\right) & \leq \psi\left(\left[\left(a_{1}+a_{2}\right)\left(q\left(u_{n-1}, u_{n}\right)\right)^{p}+a_{3}\left(q\left(u_{n}, u_{n+1}\right)\right)^{p}\right]^{1 / p}\right) \\
& <\left[\left(a_{1}+a_{2}\right)\left(q\left(u_{n-1}, u_{n}\right)\right)^{p}+\left(1-a_{1}-a_{2}\right)\left(q\left(u_{n}, u_{n+1}\right)\right)^{p}\right]^{1 / p},
\end{aligned}
$$

which is equivalent with

$$
\left(a_{1}+a_{2}\right)\left[q\left(u_{n}, u_{n+1}\right)\right]^{p}<\left(a_{1}+a_{2}\right)\left[q\left(u_{n-1}, u_{n}\right)\right]^{p},
$$

or (since $\left.a_{1}+a_{2}>0\right)$

$$
q\left(u_{n}, u_{n+1}\right)<q\left(u_{n-1}, u_{n}\right) .
$$


Using the fact that $\psi \in \Psi$ is increasing, by (13), we have

$$
q\left(u_{n}, u_{n+1}\right)<\psi\left(q\left(u_{n-1}, u_{n}\right)\right)<\psi^{2}\left(q\left(u_{n-2}, u_{n-1}\right)\right)<\ldots<\psi^{n}\left(q\left(u_{0}, u_{1}\right)\right)
$$

Let now $l \geq 1$. By using (15) and the triangle inequality, we get

$$
\begin{aligned}
q\left(u_{n}, u_{n+l}\right) & \leq q\left(u_{n}, u_{n+1}\right)+\ldots+q\left(u_{n+l-1}, u_{n+l}\right) \\
& \leq \sum_{j=n}^{n+l-1} \psi^{j}\left(q\left(u_{0}, u_{1}\right)\right) \\
& \leq \sum_{j=n}^{\infty} \psi^{j}\left(q\left(u_{0}, u_{1}\right)\right) .
\end{aligned}
$$

Letting $n \rightarrow \infty$ in the above inequality, we derive that $\sum_{j=n}^{\infty} \psi^{j}\left(q\left(u_{0}, u_{1}\right)\right) \rightarrow 0$. Hence, $q\left(u_{n}, u_{n+l}\right) \rightarrow 0$ as $n \rightarrow \infty$. Thus, $\left\{u_{n}\right\}$ is a right-Cauchy sequence in $(x, q)$.

Similarly, since

$$
\begin{aligned}
I_{p}\left(u_{n}, u_{n-1}\right) & =\left[a_{1}\left(q\left(u_{n}, u_{n-1}\right)\right)^{p}+a_{2}\left(q\left(u_{n}, T u_{n}\right)\right)^{p}+a_{3}\left(q\left(u_{n-1}, T u_{n-1}\right)\right)^{p}\right]^{1 / p} \\
& =\left[a_{1}\left(q\left(u_{n}, u_{n-1}\right)\right)^{p}+a_{2}\left(q\left(u_{n}, u_{n+1}\right)\right)^{p}+a_{3}\left(q\left(u_{n-1}, u_{n}\right)\right)^{p}\right]^{1 / p}
\end{aligned}
$$

the inequality (12) becomes

$$
\begin{aligned}
q\left(u_{n+1}, u_{n}\right) & \leq \psi\left(I_{p}\left(u_{n}, u_{n-1}\right)\right)<I_{p}\left(u_{n}, u_{n-1}\right) \\
& =\left[a_{1}\left(q\left(u_{n}, u_{n-1}\right)\right)^{p}+a_{2}\left(q\left(u_{n}, u_{n+1}\right)\right)^{p}+a_{3}\left(q\left(u_{n-1}, u_{n}\right)\right)^{p}\right]^{1 / p} .
\end{aligned}
$$

Taking into account (14), we get

$$
\begin{aligned}
\left(q\left(u_{n+1}, u_{n}\right)\right)^{p} & <a_{1}\left(q\left(u_{n}, u_{n-1}\right)\right)^{p}+a_{2}\left(q\left(u_{n}, u_{n+1}\right)\right)^{p}+a_{3}\left(q\left(u_{n-1}, u_{n}\right)\right)^{p} \\
& =a_{1}\left(q\left(u_{n}, u_{n-1}\right)\right)^{p}+a_{2}\left(q\left(u_{n}, u_{n+1}\right)\right)^{p}+\left(1-a_{1}-a_{2}\right)\left(q\left(u_{n-1}, u_{n}\right)\right)^{p} \\
& <a_{1}\left(q\left(u_{n}, u_{n-1}\right)\right)^{p}+\left(1-a_{1}\right)\left(q\left(u_{n-1}, u_{n}\right)\right)^{p}, \text { for any } n \in \mathbb{N} .
\end{aligned}
$$

We are able to examine it with the following cases.

a. If $q\left(u_{n}, u_{n-1}\right)<q\left(u_{n-1}, u_{n}\right)$ for any $n \in \mathbb{N}$, the above inequality becomes

$$
\left(q\left(u_{n+1}, u_{n}\right)\right)^{p}<\left(q\left(u_{n-1}, u_{n}\right)\right)^{p},
$$

and then, together with (15),

$$
q\left(u_{n+1}, u_{n}\right)<q\left(u_{n-1}, u_{n}\right)<\psi^{n-1}\left(u_{0}, u_{1}\right), \forall n \geq 1 .
$$

From the triangle inequality and (18), for all $l \geq 1$, we get that

$$
\begin{aligned}
q\left(u_{n+l}, u_{n}\right) & \leq q\left(u_{n+l}, u_{n+l-1}\right)+\ldots+q\left(u_{n+1}, u_{n}\right) \\
& \leq \sum_{j=n}^{n+l-1} \psi^{j}\left(q\left(u_{0}, u_{1}\right)\right) \\
& \leq \sum_{j=n}^{\infty} \psi^{j}\left(q\left(u_{0}, u_{1}\right)\right) \rightarrow 0 \text { as } n \rightarrow \infty
\end{aligned}
$$


b. If, for any $n \in \mathbb{N}, q\left(u_{n}, u_{n-1}\right) \leq q\left(u_{n-1}, u_{n}\right)$, we have

$$
q\left(u_{n+1}, u_{n}\right)<q\left(u_{n}, u_{n-1}\right)
$$

and, from (17), regarding $\psi \in \Psi$, we get that

$$
q\left(u_{n+1}, u_{n}\right)<\psi\left(q\left(u_{n}, u_{n-1}\right)\right)<\ldots<\psi^{n}\left(q\left(u_{1}, u_{0}\right)\right) .
$$

Again, by triangle inequality,

$$
\begin{aligned}
q\left(u_{n+l}, u_{n}\right) & \leq q\left(u_{n+l}, u_{n+l-1}\right)+\ldots+q\left(u_{n+1}, u_{n}\right) \\
& \leq \sum_{j=n}^{n+l-1} \psi^{j}\left(q\left(u_{1}, u_{0}\right)\right) \\
& \leq \sum_{j=n}^{\infty} \psi^{j}\left(q\left(u_{1}, u_{0}\right)\right) \rightarrow 0 \text { as } n \rightarrow \infty
\end{aligned}
$$

c. If $q\left(u_{i}, u_{i-1}\right) \leq q\left(u_{i-1}, u_{i}\right)$ for some $i \in \mathbb{N}$ and $q\left(u_{k}, u_{k-1}\right)>q\left(u_{k-1}, u_{k}\right)$ for some $k \in \mathbb{N}$, then we have for $l \in \mathbb{N}$

$$
\begin{aligned}
q\left(u_{n+l}, u_{n}\right) & \leq q\left(u_{n+l}, u_{n+l-1}\right)+\ldots+q\left(u_{n+1}, u_{n}\right) \\
& \leq \sum_{j=n}^{\infty} \psi^{j}\left(q\left(u_{1}, u_{0}\right)\right)+\sum_{j=n}^{\infty} \psi^{j}\left(q\left(u_{0}, u_{1}\right)\right) \rightarrow 0 \text { as } n \rightarrow \infty .
\end{aligned}
$$

Therefore, we proved that $\left\{u_{n}\right\}$ is a left-Cauchy in $(x, q)$.

Thus, being left and right Cauchy, the sequence $\left\{u_{n}\right\}$ is a Cauchy in complete quasi-metric space $(x, q)$, which implies that there is $u^{*} \in X$ such that

$$
\lim _{n \rightarrow \infty} q\left(u_{n}, u^{*}\right)=\lim _{n \rightarrow \infty} q\left(u^{*}, u_{n}\right)=0 .
$$

Using the continuity of $T$ and $(q 1)$, we have

$$
\begin{aligned}
& \lim _{n \rightarrow \infty} q\left(u_{n}, T u^{*}\right)=\lim _{n \rightarrow \infty} q\left(T u_{n-1}, T u^{*}\right)=0, \\
& \lim _{n \rightarrow \infty} q\left(T u^{*}, u_{n}\right)=\lim _{n \rightarrow \infty} q\left(T u^{*}, T u_{n-1}\right)=0
\end{aligned}
$$

and so

$$
\lim _{n \rightarrow \infty} q\left(u_{n}, T u^{*}\right)=\lim _{n \rightarrow \infty} q\left(T u^{*}, u_{n}\right)=0 .
$$

It follows from (20) and (21) that $T u^{*}=u^{*}$, that is, $u^{*}$ is a fixed point of $T$.

Case 2. In the case $p=0$, we have

$$
\begin{aligned}
I_{p}\left(u_{n-1}, u_{n}\right) & =\left(q\left(u_{n-1}, u_{n}\right)\right)^{a_{1}} \cdot\left(q\left(u_{n-1}, T u_{n-1}\right)\right)^{a_{2}} \cdot\left(q\left(u_{n}, T u_{n}\right)\right)^{a_{3}} \\
& =\left(q\left(u_{n-1}, u_{n}\right)\right)^{a_{1}} \cdot\left(q\left(u_{n-1}, u_{n}\right)\right)^{a_{2}} \cdot\left(q\left(u_{n}, u_{n+1}\right)\right)^{a_{3}} .
\end{aligned}
$$

Replacing in (6) and taking into account (7), we get 


$$
\begin{aligned}
q\left(u_{n}, u_{n+1}\right) & =q\left(T u_{n-1}, T u_{n}\right) \leq \alpha\left(u_{n-1}, u_{n}\right) q\left(T u_{n-1}, T u_{n}\right) \leq \psi\left(I_{p}\left(u_{n-1}, u_{n}\right)\right) \\
& <I_{p}\left(u_{n-1}, u_{n}\right)=\left(q\left(u_{n-1}, u_{n}\right)\right)^{a_{1}+a_{2}} \cdot\left(q\left(u_{n}, u_{n+1}\right)\right)^{a_{3}}
\end{aligned}
$$

and we deduce that

$$
\left(q\left(u_{n}, u_{n+1}\right)\right)^{a_{1}+a_{2}}<\left(q\left(u_{n-1}, u_{n}\right)\right)^{a_{1}+a_{2}} .
$$

Thus, taking into account $a_{1}+a_{2}>0$, we have

$$
q\left(u_{n}, u_{n+1}\right)<q\left(u_{n-1}, u_{n}\right)
$$

and, from (22), since $\psi \in \Psi$ we are able to say that, for any $n \in \mathbb{N}$,

$$
q\left(u_{n}, u_{n+1}\right) \leq \psi\left(q\left(u_{n-1}, u_{n}\right)\right)<\ldots<\psi^{n}\left(q\left(u_{0}, u_{1}\right)\right) .
$$

Following the above lines and using the triangle inequality, we obtain that the sequence $u_{n}$ is right Cauchy. Likewise, because

$$
\begin{aligned}
I_{p}\left(u_{n}, u_{n-1}\right) & \left.=\left(q\left(u_{n}, u_{n-1}\right)\right)^{a_{1}} \cdot\left(q\left(u_{n}, T u_{n}\right)\right)^{a_{2}} \cdot\left(q\left(u_{n-1}, T u_{n-1}\right)\right)^{a_{3}}\right] \\
& =\left(q\left(u_{n}, u_{n-1}\right)\right)^{a_{1}} \cdot\left(q\left(u_{n}, u_{n+1}\right)\right)^{a_{2}} \cdot\left(q\left(u_{n-1}, u_{n}\right)\right)^{a_{3}},
\end{aligned}
$$

taking into account (11) and (23), we have

$$
\begin{aligned}
q\left(u_{n+1}, u_{n}\right) & =q\left(T u_{n}, T u_{n-1}\right) \leq \alpha\left(u_{n}, u_{n-1}\right) q\left(T u_{n}, T u_{n-1}\right) \leq \psi\left(I_{p}\left(u_{n}, u_{n-1}\right)\right) \\
& <I_{p}\left(u_{n}, u_{n-1}\right)=\left(q\left(u_{n}, u_{n-1}\right)\right)^{a_{1}} \cdot\left(q\left(u_{n}, u_{n+1}\right)\right)^{a_{2}} \cdot\left(q\left(u_{n-1}, u_{n}\right)\right)^{a_{3}} \\
& <\left(q\left(u_{n}, u_{n-1}\right)\right)^{a_{1}} \cdot\left(q\left(u_{n-1}, u_{n}\right)\right)^{a_{2}+a_{3}} \\
& \leq\left(\max \left\{q\left(u_{n}, u_{n-1}\right), q\left(u_{n-1}, u_{n}\right)\right\}\right)^{a_{1}+a_{2}+a_{3}} \\
& =\max \left\{q\left(u_{n}, u_{n-1}\right), q\left(u_{n-1}, u_{n}\right)\right\} .
\end{aligned}
$$

We must examine two cases.

If $\max \left\{q\left(u_{n}, u_{n-1}\right), q\left(u_{n-1}, u_{n}\right)\right\}=q\left(u_{n-1}, u_{n}\right)$, then since $q\left(u_{n-1}, u_{n}\right)>0$, we get that

$$
q\left(u_{n+1}, u_{n}\right) \leq \psi\left(q\left(u_{n-1}, u_{n}\right)\right),
$$

and recursively

$$
q\left(u_{n+1}, u_{n}\right) \leq \psi^{n}\left(q\left(u_{0}, u_{1}\right)\right)
$$

If $\max \left\{q\left(u_{n}, u_{n-1}\right), q\left(u_{n-1}, u_{n}\right)\right\}=q\left(u_{n}, u_{n-1}\right)$, we have

$$
q\left(u_{n+1}, u_{n}\right) \leq \psi\left(q\left(u_{n}, u_{n-1}\right)\right)<\ldots<\psi^{n}\left(q\left(u_{1}, u_{0}\right)\right) .
$$

Therefore, by combining (25) with (26), we derive (due to $\left(c_{2}\right)$ ) that

$$
\lim _{n \rightarrow \infty} q\left(u_{n+1}, u_{n}\right)=\lim _{n \rightarrow \infty} \max \left\{\psi^{n}\left(q\left(u_{0}, u_{1}\right)\right), \psi^{n}\left(q\left(u_{1}, u_{0}\right)\right)\right\}=0 .
$$

Again, using the triangle inequality, and the above inequalities for all $l \geq 1$, we get

$$
\begin{aligned}
q\left(u_{n+l}, u_{n}\right) & \leq q\left(u_{n+l}, u_{n+l-1}\right)+\ldots+q\left(u_{n+1}, u_{n}\right) \\
& \leq \sum_{j=n}^{\infty} \psi^{j}\left(q\left(u_{1}, u_{0}\right)\right)+\sum_{j=n}^{\infty} \psi^{j}\left(q\left(u_{0}, u_{1}\right)\right) \rightarrow 0 \text { as } n \rightarrow \infty,
\end{aligned}
$$


that is, the sequence $\left\{u_{n}\right\}$ is left Cauchy, so that is a Cauchy sequence in a complete quasi-metric space $(x, q)$. Thus, there is $u^{*} \in X$ such that

$$
\lim _{n \rightarrow \infty} q\left(u^{*}, u_{n}\right)=0=\lim _{n \rightarrow \infty} q\left(u^{*}, u_{n}\right) .
$$

Of course, using $\left(q_{1}\right)$ and the continuity of $T$, we have $T u^{*}=u^{*}$.

Corollary 1. Let $(X, q)$ be a complete quasi-metric space, a function $\alpha: X \times X \rightarrow[0, \infty)$ and a mapping $T: X \rightarrow X$ such that there exist $\zeta \in \mathcal{Z}$ and $\psi \in \Psi$ such that, for $p \geq 0, L \geq 0$ and $a_{1}, a_{2}, a_{3} \in[0,1)$ with $a_{1}+a_{2}>0$ and $a_{1}+a_{2}+a_{3}=1$, we have

$$
\zeta\left(\alpha(u, v) q(T u, T v), \psi\left(I_{p}(u, v)+L \mathcal{N}(u, v)\right)\right) \geq 0, \text { for all distinct } u, v \in X .
$$

Suppose also that the following assumptions hold:

(i) $\quad u=$ Tu implies $\alpha(u, v)>0$ for every $v \in X$;

(ii) $v=T v$ implies $\alpha(u, v)>0$ for every $u \in X$;

(i) $T$ is $\alpha$-orbital admissible;

(ii) there exists $u_{0} \in X$ such that $\alpha\left(u_{0}, T u_{0}\right) \geq 1$ and $\alpha\left(T u_{0}, u_{0}\right) \geq 1$;

(iv) $T$ is continuous.

Then, $T$ has a fixed point.

Remark 2. Of course, in particular letting $L=0$ in the above Corollary, we find Theorem 2.1. in [16].

Corollary 2. Let $(x, q)$ be a complete quasi-metric space and a mapping $T: X \rightarrow X$ such that there exist $\zeta \in \mathcal{Z}$ and $\psi \in \Psi$ such that, for $p \geq 0, L \geq 0$ and $a_{1}, a_{2}, a_{3} \in[0,1)$ with $a_{1}+a_{2}>0$ and $a_{1}+a_{2}+a_{3}=1$, we have

$$
\zeta\left(q(T u, T v), \psi\left(I_{p}(u, v)+L \mathcal{N}(u, v)\right)\right) \geq 0, \text { for all distinct } u, v \in X .
$$

Then, Thas a fixed point.

Proof. Let $\alpha(u, v)=1$ in Corollary 1 .

Corollary 3. Let $(x, q)$ be a complete quasi-metric space, a function $\alpha: x \times x \rightarrow[0, \infty)$ and a continuous mapping $T: X \rightarrow X$ such that there exist $\psi \in \Psi$ such that, for $p \geq 0$ and $a_{1}, a_{2}, a_{3} \in[0,1)$ with $a_{1}+a_{2}>0$ and $a_{1}+a_{2}+a_{3}=1$, we have

$$
\alpha(u, v) q(T u, T v) \leq \psi\left(I_{p}(u, v)\right), \text { for all distinct } u, v \in X .
$$

Suppose that there exists $u_{0} \in X$ such that $\alpha\left(u_{0}, T u_{0}\right) \geq 1$ and $\alpha\left(T u_{0}, u_{0}\right) \geq 1$. Then, $T$ has a fixed point.

Proof. Let $\zeta(t, s)=\psi(s)-t$ in Corollary 1 .

Moreover, it easy to see that Theorem 1 is a generalization of Theorem 2.1 in [18] in the context of quasi-metric space. Indeed, if we take $L=0$ and $p=0$ in Corollary 3 , we find: 
Corollary 4. Let $(x, q)$ be a complete quasi-metric space, a function $\alpha: X \times X \rightarrow[0, \infty)$, and a continuous mapping $T: X \rightarrow X$ such that there exists $\psi \in \Psi$ such that, for $a_{1}, a_{2}, a_{3} \in[0,1)$ with $a_{1}+a_{2}>0$ and $a_{1}+a_{2}+a_{3}=1$, we have

$$
\alpha(u, v) q(T u, T v) \leq \psi\left((q(u, v))^{a_{1}} \cdot(q(u, T u))^{a_{2}} \cdot(q(v, T v))^{a_{3}}\right), \text { for all distinct } u, v \in X .
$$

Suppose that there exists $u_{0} \in X$ such that $\alpha\left(u_{0}, T u_{0}\right) \geq 1$ and $\alpha\left(T u_{0}, u_{0}\right) \geq 1$. Then, $T$ has a fixed point.

Inspired by the example of [10], we consider the following:

Example 1. Let the set $x=[1, \infty)$ and the quasi-metric $q: x \times x \rightarrow[0, \infty)$ given by

$$
q(u, v)=\left\{\begin{array}{rl}
\ln v-\ln u, & \text { if } u \leq v \\
\frac{1}{3}(\ln u-\ln v), & \text { if } u>v
\end{array} .\right.
$$

(see Example 4.1 in [10].) Let the mapping $T: x \rightarrow x$, be defined by

$$
T u=\left\{\begin{aligned}
1, & \text { if } u \in[1,2] \\
e^{u-2}, & \text { if } u \in(2, \infty)
\end{aligned}\right.
$$

and the function $\alpha: x \times x \rightarrow[0, \infty)$ be defined by

$$
\alpha(u, v)= \begin{cases}2, & \text { if } u, v \in[1,2) \\ 3, & \text { if } u=1, v=2 \text { or } u=2, v=1 \\ 6, & \text { if } u=3, v=2 \\ 0, & \text { otherwise }\end{cases}
$$

Since the mapping $T$ is continuous and for $u=2, \alpha(2, T 2)=\alpha(2,1)=3$ and $\alpha(T 2,2)=\alpha(1,2)=3$, we have that the assumptions $\left(C_{2}\right),\left(C_{3}\right)$ are satisfied. Moreover, for any $u \in[1,2)$, we have

$$
\alpha(u, T u)=\alpha(u, 1)=2 \Rightarrow \alpha\left(T 1, T^{2} 1\right)=\alpha(1,1)=2
$$

and

$$
\alpha(2, T 2)=\alpha(2,1)=3 \Rightarrow \alpha\left(T 2, T^{2} 2\right)=\alpha(1,1)=2,
$$

so that $T$ is $\alpha$-orbital admissible.

Choosing $\psi(t)=\frac{1}{3} t, p=2, a_{1}=a_{2}=a_{3}=\frac{1}{3}$ and $L=24$, we have the following cases:

Case 1. If $u, v \in[1,2]$, then $q(u, v)=q(1,1)=0$ and (3) holds for every $\zeta \in \mathcal{Z}$.

Case 2. If $u=3, v=2$, then we have

$$
\begin{aligned}
& q(3, T 3)=q(3, e)=\frac{1}{3} \ln \frac{3}{e}, \quad q(2, T 2)=q(2,1)=\frac{1}{3} \ln 2, q(T 2,2)=q(1,2)=\ln 2, \\
& q(3,2)=\frac{1}{3} \ln \frac{3}{2}, \quad q(T 3, T 2)=q(e, 1)=\frac{1}{3}, \\
& q(3, T 2)=q(3,1)=\frac{1}{3} \ln 3, \quad q(2, T 3)=q(2, e)=\ln \frac{e}{2} .
\end{aligned}
$$

Thus, we have

$$
\frac{1}{2} \min \{q(3, T 3), q(2, T 2), q(T 2,2)\}=\frac{1}{6} \ln \frac{3}{e}<\frac{1}{3} \ln \frac{3}{2}=q(3,2)
$$


and

$\alpha(3,2) q(T 3, T 2)=\frac{6}{3}<\frac{1}{3}\left[\sqrt{\frac{1}{3}}\left(\left(\frac{1}{3} \ln \frac{3}{2}\right)^{2}+\left(\frac{1}{3} \ln \frac{3}{e}\right)^{2}+\left(\frac{1}{3} \ln 2\right)^{2}\right)^{1 / 2}+24 \ln \frac{e}{2}\right]=\psi\left(I_{p}(3,2)+\operatorname{LN}(3,2)\right)$,

so that $T$ is a hybrid almost contraction for any $\zeta \in \mathcal{Z}$.

The other cases are not interesting, while $\alpha(u, v)=0$. (Consequently, the mapping $T$ has two fixed points, $u_{1}=1$ and $u_{2} \in(3,4)$.)

On the other hand, since

$$
\begin{aligned}
\alpha(3,2) q(T 3, T 2) & =2>\left(\frac{1}{3} \ln \frac{3}{2}\right)^{\gamma}\left(\frac{1}{3} \ln \frac{3}{e}\right)^{\beta}\left(\frac{1}{3} \ln 2\right)^{1-\gamma-\beta} \\
& >\psi\left((q(3,2))^{\gamma}(q(3, T 3))^{\beta},(q(2, T 2))^{1-\gamma-\beta}\right)
\end{aligned}
$$

for every $\gamma, \beta \in(0,1)$ and $\psi \in \Psi$, Theorem 2.1 in [18] can not be applied.

In particular, for the case $p=0$, the continuity condition of $T$ can be replaced with the regularity condition of the space $X$.

Theorem 2. Let $(X, q)$ be a complete quasi-metric space, a function $\alpha: x \times x \rightarrow[0, \infty)$ and a mapping $T: X \rightarrow X$ such that there exist $\zeta \in \mathcal{Z}, \psi \in \Psi, L \geq 0$ and $a_{1}, a_{2}, a_{3} \in[0,1]$ with $a_{1}+a_{2}+a_{3}=1$, such that, for all distinct $u, v \in X$, we have

$$
\begin{aligned}
& \frac{1}{2} \min \{q(u, T u), q(v, T v), q(T v, v)\} \leq q(u, v) \text { implies } \\
& \quad \zeta\left(\alpha(u, v) q(T u, T v), \psi\left((q(u, v))^{a_{1}} \cdot(q(u, T u))^{a_{2}} \cdot(q(v, T v))^{a_{3}}+L \mathcal{N}(u, v)\right)\right) \geq 0 .
\end{aligned}
$$

Suppose also that

(i) $\quad u=$ Tu implies $\alpha(u, v)>0$ for every $v \in X$;

(ii) $v=T v$ implies $\alpha(u, v)>0$ for every $u \in X$;

$\left(C_{1}\right) \quad T$ is $\alpha$-orbital admissible;

$\left(C_{2}\right)$ there exists $u_{0} \in X$ such that $\alpha\left(u_{0}, T u_{0}\right) \geq 1$ and $\alpha\left(T u_{0}, u_{0}\right) \geq 1$;

$\left(C_{3}\right) \quad x$ is regular with respect to the mapping $\alpha$.

Then, Thas a fixed point.

Proof. From the above theorem, there exists $u^{*} \in X$ such that (27) hold. In what follows, we claim that

$$
\begin{aligned}
& \frac{1}{2} \min \left\{q\left(u^{*}, T u^{*}\right), q\left(u_{n(i)}, T u_{n(i)}\right), q\left(T u_{n(i)}, u_{n(i)}\right)\right\} \leq q\left(u^{*}, u_{n(i)}\right) \quad \text { or } \\
& \frac{1}{2} \min \left\{q\left(u_{n(i)-1}, T u_{n(i)-1}\right), q\left(u^{*}, T u^{*}\right), q\left(T u^{*}, u^{*}\right)\right\} \leq q\left(u_{n(i)-1}, u^{*}\right) .
\end{aligned}
$$

Indeed, using the method of Reductio ad Absurdum, we assume that that there exists $k \in \mathbb{N}$ such that

$$
\begin{aligned}
& \frac{1}{2} \min \left\{q\left(u^{*}, T u^{*}\right), q\left(u_{k}, T u_{k}\right), q\left(T u_{k}, u_{k}\right)\right\}>q\left(u^{*}, u_{k}\right) \quad \text { and } \\
& \frac{1}{2} \min \left\{q\left(u_{k-1}, T u_{k-1}\right), q\left(u^{*}, T u^{*}\right), q\left(T u^{*}, u^{*}\right)\right\}>q\left(u_{k-1}, u^{*}\right)
\end{aligned}
$$

Therefore, we have 


$$
\begin{aligned}
q\left(u_{k-1}, u_{k}\right) & \leq q\left(u_{k-1}, u^{*}\right)+q\left(u^{*}, u_{k}\right) \\
& <\frac{1}{2} \min \left\{q\left(u_{k-1}, T u_{k-1}\right), q\left(u^{*}, T u^{*}\right), q\left(T u^{*}, u^{*}\right)\right\}+\frac{1}{2} \min \left\{q\left(u^{*}, T u^{*}\right), q\left(u_{k-1}, T u_{k-1}\right), q\left(T u_{k-1}, u_{k-1}\right)\right\} \\
& <\frac{1}{2}\left[\min \left\{q\left(u_{k-1}, u_{k}\right), q\left(u^{*}, T u^{*}\right), q\left(T u^{*}, u^{*}\right)\right\}+\min \left\{q\left(u^{*}, T u^{*}\right), q\left(u_{k-1}, u_{k}\right), q\left(u_{k}, u_{k-1}\right)\right\}\right] \\
& \leq \frac{1}{2}\left[q\left(u_{k-1}, u_{k}\right)+q\left(u_{k-1}, u_{k}\right)\right] \\
& =q\left(u_{k-1}, u_{k}\right),
\end{aligned}
$$

which is a contradiction.

In the alternative hypothesis, if the space $x$ is regular with respect to mapping $\alpha$, we have $\alpha\left(u^{*}, u_{n(i)}\right) \geq 1$, where $\left\{u_{n(i)}\right\}$ is a sub-sequence of $\left\{u_{n}\right\}$, for $i \in \mathbb{N}$. We will suppose by reductio ad absurdum that $u^{*} \neq T u^{*}$. Then, for $u=u^{*}$ and $v=u_{n(i)}$ in (3), we get

$$
\left.\zeta\left(\alpha\left(u^{*}, u_{n(i)}\right) q\left(T u^{*}, T u_{n i}\right)\right), \psi\left(\mathcal{A}_{p}\left(u^{*}, u_{n(i)}\right)\right)\right) \geq 0 .
$$

Taking into account the properties of function $\zeta, \psi$, and $\alpha$, the above relation becomes

$$
\begin{aligned}
q\left(T u^{*}, u^{*}\right) & \leq q\left(T u^{*}, T u_{n}\right)+q\left(T u_{n}, u^{*}\right) \leq \alpha\left(u^{*}, u_{n}\right) q\left(T u^{*}, T u_{n(i)}\right)+q\left(u_{n(i)+1}, u^{*}\right) \\
& \leq \psi\left(\left(q\left(u^{*}, u_{n(i)}\right)\right)^{a_{1}} \cdot\left(q\left(u^{*}, T u^{*}\right)\right)^{a_{2}} \cdot\left(q\left(u_{n(i)}, T u_{n(i)}\right)\right)^{a_{3}}+\mathcal{N}\left(u^{*}, u_{n(i)}\right)\right)+q\left(u_{n(i)+1}, u^{*}\right),
\end{aligned}
$$

Letting $i \rightarrow \infty$, we have

$0<q\left(T u^{*}, u^{*}\right)<\lim _{i \rightarrow \infty} \psi\left(\left(q\left(u^{*}, u_{n(i)}\right)\right)^{a_{1}} \cdot\left(q\left(u^{*}, T u^{*}\right)\right)^{a_{2}} \cdot\left(q\left(u_{n(i)}, T u_{n(i)}\right)\right)^{a_{3}}+\mathcal{N}\left(u^{*}, u_{n(i)}\right)\right)+q\left(u_{n(i)+1}, u^{*}\right)$

and, since $\psi$ is continuous in $0, \psi(0)=0$, we get $q\left(T u^{*}, u^{*}\right)=0$.

Corollary 5. Let $(x, q)$ be a complete quasi-metric space and $T: X \rightarrow x$ be a given mapping. Assume that there exist $L \geq 0, \zeta \in \mathcal{Z}$ and $\psi \in \Psi$ such that, for all distinct $u, v \in X$, we have

$$
\begin{aligned}
& \frac{1}{2} \min \{q(u, T u), q(v, T v) q(T v, v)\} \leq q(u, v) \text { implies } \\
& \zeta\left(q(T u, T v), \psi\left(I_{p}(u, v)+L \mathcal{N}(u, v)\right)\right) \geq 0,
\end{aligned}
$$

for all distinct $u, v \in X$. Then, $T$ has a fixed point.

Proof. It is sufficient to take $\alpha(u, v)=1$ for $u, v \in X$ in Theorem 5 .

Corollary 6. Let $(x, q)$ be a complete quasi-metric space and $T: X \rightarrow X$ be a given mapping. Assume that there exist $L \geq 0, \zeta \in \mathcal{Z}$ and $\psi \in \Psi$ such that, for all distinct $u, v \in X$, we have

$$
\frac{1}{2} \min \{q(u, T u), q(v, T v) q(T v, v)\} \leq q(u, v) \text { implies } q(T u, T v) \leq k I_{p}(u, v)
$$

for all distinct $u, v \in X$. Then, $T$ has a fixed point.

Proof. It is sufficient to take $L=0, \zeta(t, s)=k_{1} s-t, \psi(u)=k_{2} u$ with $k_{1}, k_{2} \in(0,1)$ and $k=k_{1} k_{2}$ in Corollary 5. 
Corollary 7. Let $(X, q)$ be a complete quasi-metric space and $T: X \rightarrow X$ a continuous mapping such that

$$
\begin{aligned}
& \frac{1}{2} \min \{q(u, T u), q(v, T v) q(T v, v)\} \leq q(u, v) \text { implies } \\
& q(T u, T v) \leq \frac{k}{\sqrt{3}} \cdot \sqrt{(q(u, v))^{2}+(q(u, T u))^{2}+(q(v, T v))^{2}}
\end{aligned}
$$

for all distinct $u, v \in X$ and some $k \in(0,1)$. Then, $T$ has a fixed point in $X$.

Proof. Let $p=2$ and $a_{1}=a_{2}=a_{3}=\frac{1}{3}$ in Corollary 6 .

In the next theorem, we involve a Jaggi type expression with the hybrid contractions.

Definition 2. Let $(x, q)$ be a quasi-metric space. A mapping $T: X \rightarrow X$ is called a hybrid almost contraction of type $\mathbb{J}$, if there exist $\zeta \in \mathcal{Z}$ and $\psi \in \Psi$ such that, for $p \geq 0, L \geq 0$ and $a_{1}, a_{2}>0$ with $a_{1}+a_{2}<1$, we have

$$
\begin{aligned}
& \frac{1}{2} \min \{q(u, T u), q(v, T v) q(T v, v)\} \leq q(u, v) \text { implies } \\
& \zeta\left(\alpha(u, v) q(T u, T v), \psi\left(g_{p}(u, v)+L \mathcal{N}(u, v)\right)\right) \geq 0,
\end{aligned}
$$

for all distinct $u, v \in X$, where

$$
g_{p}(u, v)=\left\{\begin{array}{cc}
{\left[a_{1}(q(u, v))^{p}+a_{2}\left(\frac{q(u, T u)) \cdot(q(v, T v)}{q(u, v)}\right)^{p}\right]^{1 / p},} & \text { for } p>0 \\
(q(u, v))^{a_{1}} \cdot(q(u, T u))^{a_{1}} \cdot(q(v, T v))^{1-a_{1}-a_{2},} & \text { for } p=0
\end{array}\right.
$$

and

$$
\mathcal{N}(u, v)=\min \{q(u, T v), q(v, T u)\} .
$$

Theorem 3. Let $(X, q)$ be a complete quasi-metric space and $\alpha: X \times X \rightarrow[0, \infty)$ be a mapping such that:

(i) $\quad u=T u$ implies $\alpha(u, v)>0$ for every $v \in X$;

(ii) $v=T v$ implies $\alpha(u, v)>0$ for every $u \in X$.

Suppose that $T: X \rightarrow X$ is a hybrid almost contraction of type $\mathbb{J}$ such that the following assumptions hold:

(i) $T$ is $\alpha$-orbital admissible;

(ii) there exists $u_{0} \in X$ such that $\alpha\left(u_{0}, T u_{0}\right) \geq 1$ and $\alpha\left(T u_{0}, u_{0}\right) \geq 1$;

(iii) there exists $\Delta>0$ such that, $\left(a_{1}+a_{2} \Delta^{2 p}\right)^{1 / p} \leq 1$ (where $p>0$ ) and

$$
\frac{1}{\Delta} q(u, v) \leq q(v, u) \leq \Delta q(u, v), \text { for all } u, v \in X
$$

(iv) $T$ is continuous.

Then, T has a fixed point.

Proof. We will consider only the case $p>0$ because, for $p=0$, the expression is similar to the one in Theorem 1. By verbatim of the first lines in the proof of Theorem 1 , starting from a point $u_{0}$, we are able to build a sequence $\left\{u_{n}\right\} \subset X$. Onward, as in the proof of Theorem 1, we suppose that $u_{n+1} \neq u_{n}$ for all $n \in \mathbb{N}$ and from (35), we have $\frac{1}{2} \min \left\{q\left(u_{n-1}, T u_{n-1}\right), q\left(u_{n}, T u_{n}\right), q\left(T u_{n}, u_{n}\right)\right\} \leq q\left(u_{n-1}, u_{n}\right)$, which implies

$$
\zeta\left(\alpha\left(u_{n-1}, u_{n}\right) q\left(T u_{n-1}, T u_{n}\right), \psi\left(g_{p}\left(u_{n-1}, u_{n}\right)+L \mathcal{N}\left(u_{n-1}, u_{n}\right)\right)\right) \geq 0 .
$$


By the axiom $\left(z_{d}\right)$, Lemma 1 and taking into account (7), this inequality becomes

$$
\begin{aligned}
q\left(u_{n}, u_{n+1}\right) & \leq \alpha\left(u_{n-1}, u_{n}\right) q\left(T u_{n-1}, T u_{n}\right) \leq \psi\left(g_{p}\left(u_{n-1}, u_{n}\right)+L \mathcal{N}\left(u_{n-1}, u_{n}\right)\right)<g_{p}\left(u_{n-1}, u_{n}\right) \\
& =\left[a_{1}\left(q\left(u_{n-1}, u_{n}\right)\right)^{p}+a_{2}\left(\frac{q\left(u_{n-1}, T u_{n-1}\right) \cdot q\left(u_{n}, T u_{n}\right)}{q\left(u_{n-1}, u_{n}\right)}\right)^{p}\right]^{1 / p} \\
& =\left[a_{1}\left(q\left(u_{n-1}, u_{n}\right)\right)^{p}+a_{2}\left(\frac{q\left(u_{n-1}, u_{n}\right) \cdot\left(q u_{n}, u_{n+1}\right)}{q\left(u_{n-1}, u_{n}\right)}\right)^{p}\right]^{1 / p} \\
& =\left[a_{1}\left(q\left(u_{n-1}, u_{n}\right)\right)^{p}+a_{2}\left(q\left(u_{n}, u_{n+1}\right)\right)^{p}\right]^{1 / p} .
\end{aligned}
$$

Thereupon,

$$
q\left(u_{n}, u_{n+1}\right)<\left(\frac{a_{1}}{1-a_{2}}\right)^{1 / p} q\left(u_{n-1}, u_{n}\right)<q\left(u_{n-1}, u_{n}\right)
$$

and then, from (36), we have $q\left(u_{n}, u_{n+1}\right)<\psi\left(q\left(u_{n-1}, u_{n}\right)\right)$. Since $\psi \in \Psi$, recursively, we get

$$
q\left(u_{n}, u_{n+1}\right)<\psi\left(q\left(u_{n-1}, u_{n}\right)\right)<\ldots<\psi^{n}\left(q\left(u_{0}, u_{1}\right)\right) .
$$

In order to prove that $\left\{u_{n}\right\}$ is a right-Cauchy sequence, let $l \in \mathbb{N}$. From (37) and the triangle inequality, we get that

$$
\begin{aligned}
q\left(u_{n}, u_{n+l}\right) & \leq q\left(u_{n}, u_{n+1}\right)+\ldots+q\left(u_{n+l-1}, u_{n+l}\right) \\
& \leq \sum_{j=n}^{n+l-1} \psi^{j}\left(q\left(u_{0}, u_{1}\right)\right) \\
& \leq \sum_{j=n}^{\infty} \psi^{j}\left(q\left(u_{0}, u_{1}\right)\right) \rightarrow 0, \text { as } n \rightarrow \infty .
\end{aligned}
$$

We conclude that $\left\{q_{n}\right\}$ is a right-Cauchy sequence in $(x, q)$.

Substituting in (35) $u=u_{n}$ and $v=u_{n-1}$ and since $\frac{1}{2} \min \left\{q\left(u_{n}, T u_{n}, q\left(u_{n-1}, T u_{n-1}\right), q\left(T u_{n-1}, u_{n-1}\right)\right)\right\} \leq$ $q\left(u_{n}, u_{n-1}\right)$, we have (taking into account (11))

$$
\begin{aligned}
q\left(u_{n+1}, u_{n}\right) & \leq \alpha\left(u_{n}, u_{n-1}\right) q\left(T u_{n}, T u_{n-1}\right) \leq \psi\left(g_{p}\left(u_{n}, u_{n-1}\right)+L \mathcal{N}\left(u_{n}, u_{n-1}\right)\right)<g_{p}\left(u_{n}, u_{n-1}\right) \\
& =\left[a_{1}\left(q\left(u_{n}, u_{n-1}\right)\right)^{p}+a_{2}\left(\frac{\left.q\left(u_{n}, u_{n+1}\right)\right) \cdot\left(q\left(u_{n-1}, u_{n}\right)\right.}{q\left(u_{n}, u_{n-1}\right.}\right)^{p}\right]^{1 / p}
\end{aligned}
$$

i.e.,

$$
\left(q\left(u_{n+1}, u_{n}\right)\right)^{p}<a_{1}\left(q\left(u_{n}, u_{n-1}\right)\right)^{p}+a_{2}\left(\frac{\left.q\left(u_{n}, u_{n+1}\right)\right) \cdot\left(q\left(u_{n-1}, u_{n}\right)\right.}{q\left(u_{n}, u_{n-1}\right.}\right)^{p} .
$$

On one hand, we have already proved that $q\left(u_{n}, u_{n+1}\right)<q\left(u_{n-1}, u_{n}\right)$. On the other hand, by (iii), there exists a positive constant $\Delta$ such that $q\left(u_{n-1}, u_{n}\right) \leq \Delta q\left(u_{n}, u_{n-1}\right)$ for $n \in \mathbb{N}$. Thus, we have

$$
\begin{aligned}
\left(q\left(u_{n+1}, u_{n}\right)\right)^{p} & \left.<a_{1}\left(q\left(u_{n}, u_{n-1}\right)\right)^{p}+a_{2}\left(\frac{\left(q\left(u_{n-1}, u_{n}\right)\right)^{2}}{q\left(u_{n}, u_{n-1}\right.}\right)\right)^{p} \\
& <a_{1}\left(q\left(u_{n}, u_{n-1}\right)\right)^{p}+a_{2}\left(\frac{\left(\Delta \cdot q\left(u_{n}, u_{n-1}\right)\right)^{2}}{q\left(u_{n}, u_{n-1}\right)}\right)^{p} \\
& =\left(a_{1}+a_{2} \Delta^{2 p}\right) \cdot\left(q\left(u_{n}, u_{n-1}\right)\right)^{p},
\end{aligned}
$$

which is equivalent to the next inequality

$$
q\left(u_{n+1}, u_{n}\right)<\left(a_{1}+a_{2} \Delta^{2 p}\right)^{1 / p} q\left(u_{n}, u_{n-1}\right) \leq q\left(u_{n}, u_{n-1}\right) .
$$


Thus,

$$
q\left(u_{n+1}, u_{n}\right)<\psi\left(q\left(u_{n}, u_{n-1}\right)\right)<\ldots<\psi^{n}\left(q\left(u_{1}, u_{0}\right)\right)
$$

Again, considering triangle inequality, together with (38), for $l \in \mathbb{N}$, we have

$$
\begin{aligned}
q\left(u_{n+l}, u_{n}\right) & \leq q\left(u_{n+l}, u_{n+l-1}\right)+\ldots+q\left(u_{n-1}, u_{n}\right) \\
& \leq \sum_{j=n}^{\infty} \psi^{j}\left(q\left(u_{0}, u_{1}\right)\right) \rightarrow 0, \text { as } n \rightarrow \infty .
\end{aligned}
$$

Analogously, we deduce that $\left\{u_{n}\right\}$ is left-Cauchy, so that it is a Cauchy sequence in complete quasi-metric space.

Thus, there exists $u^{*} \in X$ such that

$$
\lim _{n \rightarrow \infty} q\left(u_{n}, u^{*}\right)=\lim _{n \rightarrow \infty} q\left(u^{*}, u_{n}\right)=0 .
$$

Under the assumption (iv), from the continuity of $T$ and $\left(q_{1}\right)$, we have

$$
\begin{aligned}
& \lim _{n \rightarrow \infty} q\left(u_{n}, T u^{*}\right)=\lim _{n \rightarrow \infty} q\left(T u_{n-1}, T u^{*}\right)=0, \\
& \lim _{n \rightarrow \infty} q\left(T u^{*}, u_{n}\right)=\lim _{n \rightarrow \infty} q\left(T u^{*}, T u_{n-1}\right)=0
\end{aligned}
$$

so that

$$
\lim _{n \rightarrow \infty} q\left(u_{n}, T u^{*}\right)=\lim _{n \rightarrow \infty} q\left(T u^{*}, u_{n}\right)=0 .
$$

Hence, $T u^{*}=u^{*}$ that is, $u^{*}$ is a fixed point of $T$.

The following is a special case for $p=0$.

Corollary 8. Let $(X, q)$ be a complete quasi-metric space, a function $\alpha: X \times X \rightarrow[0, \infty)$ and a mapping $T: X \rightarrow X$ such that there exist $\zeta \in \mathcal{Z}$ and $\psi \in \Psi$ such that, for $p \geq 0, L \geq 0$ and $a_{1}, a_{2}, \in[0,1)$ with $a_{1}+a_{2}<1$, we have

$$
\zeta\left(\alpha(u, v) q(T u, T v), \psi\left(g_{p}(u, v)+L \mathcal{N}(u, v)\right)\right) \geq 0, \text { for all distinct } u, v \in X .
$$

Suppose also that the following assumptions hold:

(i) $\quad u=$ Tu implies $\alpha(u, v)>0$ for every $v \in X$;

(ii) $v=T v$ implies $\alpha(u, v)>0$ for every $u \in X$;

(i) $T$ is $\alpha$-orbital admissible;

(ii) there exists $u_{0} \in X$ such that $\alpha\left(u_{0}, T u_{0}\right) \geq 1$ and $\alpha\left(T u_{0}, u_{0}\right) \geq 1$;

(iii) there exists $\Delta>0$ such that, $\left(a_{1}+a_{2} \Delta^{2 p}\right)^{1 / p} \leq 1$ (where $p>0$ ) and

$$
\frac{1}{\Delta} q(u, v) \leq q(v, u) \leq \Delta q(u, v), \text { for all } u, v \in X ;
$$

(iv) $T$ is continuous.

Then, T has a fixed point. 
Example 2. Let $x=[0,1]$ and the function

$$
q(u, v)=\left\{\begin{array}{cc}
u-v, & \text { for } u \geq v \\
2(v-u), & \text { for } u<v
\end{array}\right.
$$

It is easy to see that the pair $(x, q)$ forms a quasi-metric space.

Let the map $T: X \rightarrow X$ defined by

$$
T u= \begin{cases}\frac{1}{8}, & \text { for } u \in\left[0, \frac{1}{2}\right] \\ \frac{u}{4}, & \text { for } u \in\left[\frac{1}{2}, 1\right]\end{cases}
$$

and choose $\zeta(u, v)=\frac{1}{2} v-u$ and $\psi(t)=\frac{1}{2}$ t. For $p=2, L=0, \Delta=2, a_{1}=\frac{1}{4}$ and $a_{2}=\frac{1}{32}$ because $\left(a_{1}+a_{2} \cdot \Delta^{2 p}\right)^{1 / p}=\frac{1}{4}+\frac{1}{32} \cdot 2^{4}=\frac{3}{4} \leq 1$, the assumption (iii) is satisfied. In this case, $(41)$ becomes

$$
\alpha(u, v) q(u, v) \leq g_{p}(u, v)=\frac{1}{4} \sqrt{\frac{1}{4}(q(u, v))^{2}+\frac{1}{32}\left(\frac{q(u, T u) q(v, T v)}{q(u, v)}\right)^{2}} .
$$

Define $\alpha: x \times x \rightarrow[0, \infty)$ such that

$$
\alpha(u, v)=\left\{\begin{array}{cc}
3, & \text { for } u, v \in\left[0, \frac{1}{2}\right) \\
1, & \text { for } u=1, v=0 \\
0, & \text { otherwise }
\end{array}\right.
$$

It is easy to see that $T$ is $\alpha$-admissible. Indeed, we have

$$
\alpha(u, v)=3 \Rightarrow \alpha(T u, T v)=\alpha(1 / 8,1 / 8)=3, \text { for } u, v \in\left[0, \frac{1}{2}\right)
$$

and

$$
\alpha(1,0)=1 \Rightarrow \alpha(T 1, T 0)=\alpha(1 / 4,1 / 8)=3 .
$$

On the other hand, for $q_{0}=0$,

$$
\alpha(0, T 0)=\alpha(T 0,0)=\alpha(0,0)=3,
$$

so that the presumptions $(i),(i i)$, and ( $i v)$ are satisfied. Of course, if $u, v \in\left[0, \frac{1}{2}\right)$, we have $q(T u, T v)=q\left(\frac{1}{8}, \frac{1}{8}\right)=0$ and (41) is verified. For $u=1$ and $v=0$, we have $q(T 1$, To $)=\frac{1}{4}-\frac{1}{8}=\frac{1}{8}, q(0, T 0)=q(0,1 / 8)=2(1 / 8-0)=$ $1 / 4, q(1, T 1)=q(1,1 / 4)=3 / 4$ and

$$
\begin{aligned}
\alpha(1,0) q(T 1, T 0) & =\frac{1}{8} \leq \frac{1}{4} \sqrt{\frac{1}{4}+\frac{1}{32}\left(\frac{3}{16}\right)^{2}} \\
& =\frac{1}{4} \sqrt{\frac{1}{4}(q(1,0))^{2}+\frac{1}{32}\left(\frac{q(0, T 0) q(1, T 1)}{q(1,0)}\right)^{2}}
\end{aligned}
$$

The other cases are not interesting since $\alpha(u, v)=0$ and the condition (42) is fulfilled trivially. Thus, the presumptions of Theorem 8 are provided and $u=\frac{1}{8}$ is the fixed point of $T$.

Corollary 9. Let $(x, q)$ be a complete quasi-metric space and $T$ be a continuous self-mapping on $X$. Suppose that there exist $\zeta \in \mathcal{Z}, \psi \in \Psi$ such that

$$
\zeta\left(q(T u, T v), \psi\left(g_{p}(u, v)\right)\right) \geq 0
$$


for each distinct $u, v \in X$. If there exists $\Delta>0$ such that $\left(a_{1}+a_{2} \cdot \Delta^{2 p}\right)^{1 / p} \leq 1$ for $p>0$, and $\frac{1}{\Delta} q(u, v) \leq$ $q(v, u) \leq \Delta q(u, v)$ for all $u, v \in X$, then $T$ has a fixed point.

Proof. It is sufficient to take $L=0$ and $\alpha(u, v)=1$ for $u, v \in X$ in Corollary 8.

Corollary 10. Let $(x, q)$ be a complete quasi-metric space and $T$ be a self-mapping on $x$. Suppose that there exists $\Delta>0$ such that $\left(a_{1}+a_{2} \cdot \Delta^{2 p}\right)^{1 / p} \leq 1$ for $p>0$, and $\frac{1}{\Delta} q(u, v) \leq q(v, u) \leq \Delta q(u, v)$ for all $u, v \in x$. The mapping $T$ has a fixed point provided that

$$
q(T u, T v) \leq c \cdot g_{p}(u, v)
$$

for each distinct $u, v \in X$ and some $c \in(0,1)$.

Proof. We set $\zeta(t, s)=c_{1} s-t, \psi(u)=c_{2} u$ with $c_{1}, c_{2} \in[0,1)$ and $c=c_{1}+c_{2}$ in Corollary 9 .

Remark 3. Letting $p=0$ in Corollary 10, we find Theorem 2.2. in [20].

Example 3. Let $(x, q)$ be the quasi-metric space, where $x=[1, \infty)$ and

$$
q(u, v)=\left\{\begin{array}{cc}
u-v, & \text { for } u \geq v \\
2(v-u), & \text { for } u<v
\end{array}\right.
$$

Let

$$
T u=\left\{\begin{aligned}
u^{3}-8 u^{2}+19 u-9, & \text { for } u \in[1,5] \\
\ln \left(u^{2}-24\right)+u+6, & \text { for } u \in(5, \infty) .
\end{aligned}\right.
$$

Consider the function $\zeta$ be arbitrary in $\mathcal{Z}, \psi \in \Psi$ with $\psi(t)=\frac{t}{\sqrt{3}}$ and $\alpha: x \times x \rightarrow[0, \infty)$ such that

$$
\alpha(u, v)=\left\{\begin{array}{cc}
u^{2}+1, & \text { for }(u, v) \in\{(3,3),(3,4),(4,3),(3,1),(1,3)\} \\
1, & \text { for }(u, v)=(2,1) \\
0, & \text { otherwise }
\end{array}\right.
$$

It is easily verified that $T$ is $\alpha$-orbital admissible. Whereas $T 1=T 3=T 4=3$, taking into account the definition of function $\alpha$, we have that the inequality (41) holds for every pair $(u, v) \in X^{2} \backslash\{(2,1)\}$. For the case $u=2$ and $v=1$, choosing $a_{1}=\frac{1}{2}, a_{2}=\frac{1}{48}$ and $p=2$, we find that axiom (iii) holds. On the other hand,

$$
\begin{aligned}
g_{p}(2,1) & =\left[\frac{1}{2}(q(2,1))^{2}+\frac{1}{48}\left(\frac{q(2, T 2) \cdot q(1, T 1)}{q(2,1)}\right)^{2}\right]^{1 / 2} \\
& =\sqrt{\frac{1}{2}+\frac{1}{48} \cdot\left(\frac{q(2,5) \cdot q(1,3)}{q(2,1)}\right)^{2}}=\sqrt{\frac{25}{2}}
\end{aligned}
$$

and

$$
\alpha(2,1) q(T 2, T 1)=q(5,3)=2<\sqrt{\frac{25}{6}}=\psi\left(g_{p}(2,1)\right) .
$$

Consequently, by Theorem 8, we have that the mapping $T$ has a fixed point in $X$. 
On the other hand, we can observed that, for $u=1$ and $v=5$,

$$
q(T 1, T(4.5))=q(2,5.625)=7.25, q(1, T 1)=q(1,2)=2, q(4.5, T(4.5))=q(4.5,5.625)=1.125,
$$

so that, since

$$
q(T 1, T(4.5))>\lambda(q(1, T 1))^{\alpha}(q(4.5, T(4.5)))^{1-\alpha}
$$

for any $\lambda \in[0,1)$ and $\alpha \in(0,1)$, Theorem 2.2 in [20] can not be applied.

Corollary 11. Let $(X, q)$ be a complete quasi-metric space and $T: X \rightarrow X$ a continuous mapping. Then, $T$ has a fixed point provided that

$$
q(T u, T v) \leq k_{1} \cdot q(u, v)+k_{2} \cdot \frac{q(u, T u) q(v, T v)}{q(u, v)}
$$

for each $u, v \in X$ and $k_{1}, k_{2} \in(0,1)$ with $k_{1}+k_{2}<1$

Proof. Let $p=1$ and $k_{i}=c \cdot a_{i}$, for $i \in\{1,2\}$ in Corollary 10 .

Author Contributions: All authors contributed equally and significantly in writing this article. Writing-original draft, A.F. and E.K.; writing - review and editing, A.F., G.P., and E.K. All authors have read and agreed to the published version of the manuscript.

Funding: This research received no external funding.

Acknowledgments: The authors thank the anonymous referees for their remarkable comments, suggestions, and ideas that helped to improve this paper.

Conflicts of Interest: The authors declare no conflict of interest.

\section{References}

1. Wilson, W.A. On quasi-metric spaces. Am. J. Math. 1931, 53, 675-684. [CrossRef]

2. Künzi, H.-P.A. Nonsymmetric distances and their associated withpologies: about the origins of basic ideas in the area of asymmetric topology. In Handbook of the History of General Topology; volume 3 of Hist. Topol.; Kluwer Acad. Publ.: Dordrecht, The Netherlands, 2001; pp. 853-968.

3. Künzi, H.-P.A.; Vajner, V. Weighted quasi-metrics. In Papers on General Topology and Applications (Flushing, NY, 1992); New York Acad. Sci.: New York, NY, USA, 1994; pp. 64-77.

4. Künzi, H.-P.A.; Romaguera, S. Quasi-Metric Spaces, Quasi-Metric Hyperspaces and Uniform Local Compactness. Rend. Istit. Mat. Univ. Trieste Suppl. 1999, XXX, 133-144.

5. Romaguera, S.; Schellekens, M. On the structure of the dual complexity space: the general case. Extracta Math. 1998, 13, 249-253.

6. Romaguera, S.; Schellekens, M. Quasi-metric properties of complexity spaces. Topology Appl. 1999, 98, 311-322. [CrossRef]

7. Romaguera, S.; Schellekens, M. Duality and quasi-normability for complexity spaces. Appl. Gen. Topol. 2002, 3, 91-112. [CrossRef]

8. Romaguera, S.; Schellekens, M.P. Weightable quasi-metric semigroups and semilattices. Electr. Notes Theor. Comput. Sci. 2001, 40, 347-358. [CrossRef]

9. Stojmirović, A. Quasi-metrics, Similarities and Searches: aspects of geometry of protein datasets. arXiv 2018, arXiv:0810.5407.

10. Secelean, N.A.; Mathew, S.; Wardowski, D. New fixed point results in quasi-metric spaces and applications in fractals theory. Adv. Differ. Equ. 2019, 2019, 177. [CrossRef]

11. Romaguera, S.; Tirado, P. A characterization of Smyth complete quasi-metric spaces via Caristi's fixed point theorem. Fixed Point Theory Appl. 2015, 2015, 183. [CrossRef] 
12. Romaguera , S.; Tirado, P. The Meir-Keeler fixed point theorems for quasi-metric spaces and some consequences. Symmetry 2019, 11, 741. [CrossRef]

13. Rus, I.A. Generalized Contractions and Applications; Cluj University Press: Cluj-Napocca, Romania, 2001.

14. Bianchini, R.M.; Grandolfi, M. Transformazioni di tipo contracttivo generalizzato in uno spazio metrico. Atti Acad. Naz. Lincei VII. Ser. Rend. Cl. Sci. Fis. Mat. Natur. 1968, 45, 212-216.

15. Popescu, O. Some new fixed point theorems for $\alpha$-Geraghty contractive type maps in metric spaces. Fixed Point Theory Appl. 2014, 2014, 190. [CrossRef]

16. Agarwal, R.P.; Karapinar, E. Interpolative Rus-Reich-Ciric type contractions via simulation functions. An. St. Univ. Ovidius Constanta Ser. Mat. 2020, in press.

17. Aydi, H.; Chen, C.M.; Karapinar, E. Interpolative Ciric-Reich-Rus type contractions via the Branciari distance. Mathematics 2019, 7, 84. [CrossRef]

18. Aydi, H.; Karapinar, E.; Roldán López de Hierro, A.F. $\omega$ Interpolative Ciric-Reich-Rus type contractions. Mathematics 2019, 7, 57. [CrossRef]

19. Jaggi, D.S. Some unique fixed point theorems. Indian J. Pure Appl. Math. 1977, 8, 223-230.

20. Karapinar, E. Revisiting the Kannan type contractions via interpolation. Adv. Theory Nonlinear Anal. Appl. 2018, 2, 85-87. [CrossRef]

21. Karapinar, E.; Alqahtani, O.; Aydi, H. On Interpolative Hardy-Rogers type contractions. Symmetry 2019, 11, 8. [CrossRef]

22. Karapinar, E.; Agarwal, R.P.; Aydi, H. Interpolative Reich-Rus-Ciric type contractions on partial metric spaces. Mathematics 2018, 6, 256. [CrossRef]

23. Khojasteh, F.; Shukla, S.; Radenović, S. A new approach to the study of fixed point theorems via simulation functions. Filomat 2015, 29, 1189-1194. [CrossRef]

24. Petruşel, A.; Rus, I.A. Fixed point theory in terms of a metric and of an order relation. Fixed Point Theory 2019, 20, 601-622. [CrossRef]

25. Rus, I.A.; Petruşel, A.; Petruşel, G. Fixed Point Theory; Cluj University Press: Cluj-Napocca, Romania, 2008.

(C) 2020 by the authors. Licensee MDPI, Basel, Switzerland. This article is an open access article distributed under the terms and conditions of the Creative Commons Attribution (CC BY) license (http:/ / creativecommons.org/licenses/by/4.0/). 